\title{
Chapter 2 \\ Transfer of Radiocesium to Rice in Contaminated Paddy Fields
}

\author{
Keisuke Nemoto and Naoto Nihei
}

\begin{abstract}
Rice contaminated with high concentrations of radiocesium was found in some local areas after the nuclear accident in Fukushima Prefecture in 2011. Here we discuss the issues of cultivating rice in contaminated areas through our field experiments. The transfer of radiocesium to commercial rice has been artificially down-regulated by potassium fertilizer in radiocesium-contaminated areas in Fukushima. Since 2012, we have continued to cultivate rice experimentally in paddy fields under conventional fertilizer to trace the annual change of radiocesium uptake. The radiocesium concentration in rice cultivated under conventional fertilizer has seen almost no change since 2013. One of the reasons for this is that radiocesium fixation in soil has hardly progressed in these paddy fields.
\end{abstract}

Keywords Paddy field $\cdot$ Radiocesium $\cdot$ Rice

\subsection{Radiocesium in the Paddy Field Ecosystem}

The Fukushima Daiichi Nuclear Power Plant Accident in March 2011 caused extensive radiation exposure to fields in Fukushima Prefecture. A large proportion of the released radiation consisted of two radionuclides, namely ${ }^{137} \mathrm{Cs}$ and ${ }^{134} \mathrm{Cs} .{ }^{137} \mathrm{Cs}$ is of most concern because of its long half-life (30.2 years), and thus a long-term problem for agriculture.

One of the most important agricultural products produced in Fukushima Prefecture is rice, which accounts for $40 \%$ of total food production from this prefecture. Rice contaminated with high concentrations of radiocesium was found in some local areas after the nuclear accident, and thus it was necessary to take immediate measures to reduce radiocesium uptake in rice. As an aquatic plant, rice has developed specific physiological and ecological characteristics to take up nutrients, and the ecosystem of the paddy field has also its own unique characteristics regarding

K. Nemoto $(\bowtie) \cdot$ N. Nihei

Graduate School of Agricultural and Life Sciences, The University of Tokyo,

Bunkyo-ku, Tokyo, Japan

e-mail: unemoto@mail.ecc.u-tokyo.ac.jp 
material cycle, such as nitrogen, phosphorus, potassium, etc. Therefore, research conducted in the aftermath of the Chernobyl nuclear accident related to agriculture was not applicable to the situation in Fukushima. Here we discuss the issues of cultivating rice in contaminated fields through a series of experiments carried out in Fukushima Prefecture.

\subsection{Transfer of Radiocesium to Rice in 2011 (After the Accident)}

In 2011, cultivation of rice was restricted in the areas where the soil contained $5000 \mathrm{~Bq} / \mathrm{kg}$ of radiocesium. The concentration of radiocesium in rice produced outside the restricted areas was low, and the governor of Fukushima Prefecture announced that the rice cultivated in Fukushima Prefecture was safe in the fall of 2011. However, in the fall of 2011 after this announcement, rice with radiocesium concentration exceeding the provisional regulation level of $500 \mathrm{~Bq} / \mathrm{kg}$ was found in the northern part of the Abukuma highland in Fukushima Prefecture. Strangely, there were cases where rice cultivated in one paddy field contained several hundred $\mathrm{Bq} / \mathrm{kg}$ of radiocesium and rice cultivated in an adjacent field had radiocesium concentrations below the detection limit. It was difficult to infer the reason for such a wide variation in radiocesium uptake, even after consulting the literature related to the Chernobyl accident.

\subsection{Experimental Cultivation in $\mathbf{2 0 1 2}$}

Because rice had been detected with over $500 \mathrm{~Bq} / \mathrm{kg}$ of radiocesium in 2011, rice cultivation was restricted in many regions in 2012. However, local municipalities began 'experimental cultivation'. The basic purpose of these experiments were to investigate the effect of applying potassium fertilizer which was thought to reduce radiocesium uptake. Potassium is one of the three major nutrients for plants along with nitrogen and phosphorus, and it is usually applied as a compound fertilizer containing nitrogen and phosphorus, not as a straight fertilizer. Although plants do not require cesium as a nutrient, it is inadvertently taken up instead of potassium because both elements share similar chemical characteristics. Generally, this 'accidental uptake' of cesium can occur more frequently as there is less the exchangeable potassium (extracted with $1 \mathrm{~mol} \mathrm{~L}^{-1}$ ammonium acetate) that plants can absorb in the soil.

Thus, in the experimental cultivation in 2012, a sufficient amount of potassium fertilizer was applied to the paddy fields where the radiocesium-contaminated rice was found in 2011. Rice was experimentally cultivated in these paddy fields after applying fertilizer to confirm whether radiocesium concentration in the grain was lower than the maximum limit for shipment $(<100 \mathrm{~Bq} / \mathrm{kg}$, adopted in 2012). When 
the concentration was confirmed to be lower than the maximum limit in this experiment, the prefecture allowed farmers to cultivate rice commercially from the following year (2013) with a prerequisite that potassium fertilizer would be applied.

The result of the experiment in 2012 demonstrated that applying potassium fertilizer thoroughly can reduce the transfer of radiocesium to rice effectively even in radiocesium-contaminated areas (Ministry of Agriculture, Forestry and Fisheries, and Fukushima Prefecture 2014). Indeed, brown rice with radiocesium levels over $100 \mathrm{~Bq} / \mathrm{kg}$ were detected in only 71 bags $(0.0007 \%)$ out of whole commercial rice (a total of about 10 million bags) produced in Fukushima in 2012, due to the thorough application of potassium fertilizer all over the prefecture (Nihei et al. 2015).

\subsection{The Experimental Cultivation in Oguni, Date City}

As stated above, the reason rice had a high concentration of radiocesium is now better understood, and this knowledge helped to pave the way for the resumption of rice cultivation in 2013. However, not all problems were resolved by the experimental cultivation. When uptake of radiocesium is down-regulated by the application of potassium as was seen in the experimental cultivation, it becomes difficult to identify the specific reason why the radiocesium concentration of rice differs for each paddy field within an area. Furthermore, to decide the timing of ceasing potassium application in the future, it will be important to ensure that radiocesium remaining in fields will not be absorbed by crops under conventional fertilizer use. Hence, it is necessary to trace the annual change of radiocesium uptake in rice in the natural paddy field ecosystem under conventional fertilizer use.

Oguni in Date City is a district where rice with radiocesium over $500 \mathrm{~Bq} / \mathrm{kg}$ was harvested in 2011. Date City and the local community of Oguni appreciated the importance of the research into radiocesium uptake in the natural paddy field ecosystem and gave their support for our project. In this way, our research group in the University of Tokyo, Koyama group (agricultural economics) in the University of Fukushima, and Gotoh group (pedology) in Tokyo University of Agriculture collaborated and carried out the experimental cultivation in Oguni from 2012.

Oguni is located in hilly terrain in the north of the Abukuma highlands, and the Oguni River runs through the center of the district. During periods of water shortage in the basin of the tributaries of the Oguni River, numerous reservoirs are frequently used to supply water to the paddy fields. Sixty paddy fields were selected in different geographical locations encompassing a variety of different local environments. Potassium silicate and zeolite (each $200 \mathrm{~g} / \mathrm{m}^{2}$ ) were applied to 5 of the 60 paddy fields as a radiocesium reduction measure, whereas the remaining 55 paddy fields were cultivated under conventional fertilizer usage; however, in each of these 55 fields, $6.6 \mathrm{~m}^{2}$ of land was separated from the rest of the field using corrugated sheets to investigate the effect of applying potassium silicate $\left(200 \mathrm{~g} / \mathrm{m}^{2}\right)$ (Fig. 2.1). In the fall of 2012, we measured the radiocesium concentration in the rice cultivated under 


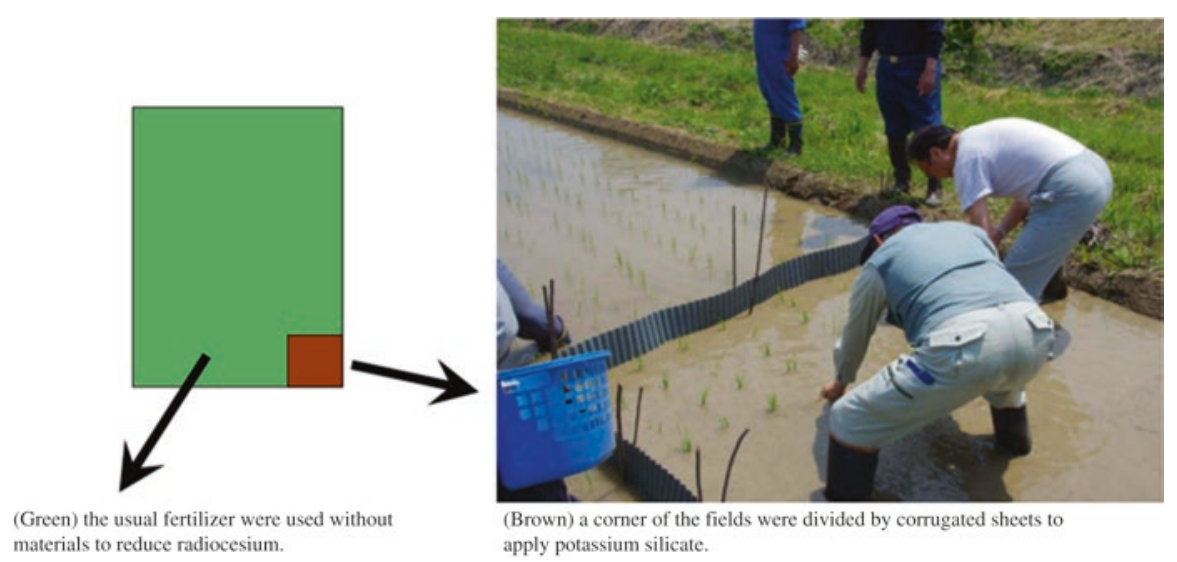

Fig. 2.1 The experiment planning of paddy fields in Oguni

normal fertilizer usage. Forty-one of the 55 paddy fields produced brown rice with less than $100 \mathrm{~Bq} / \mathrm{kg}$ of radiocesium. Some of these paddy fields had produced rice with several hundred $\mathrm{Bq} / \mathrm{kg}$ of radiocesium one year earlier. Judging from this result, it seemed that the uptake of radiocesium in rice cultivated in Oguni had decreased over time.

Soils in the paddy fields that produced rice with high radiocesium concentrations typically contained exchangeable potassium less than $10 \mathrm{mg} \mathrm{K}_{2} \mathrm{O} / 100 \mathrm{~g}$, and thus it was confirmed that potassium concentration in paddy fields was an important factor to reduce radiocesium contamination in rice. An interesting finding was that the paddy fields that produced rice with high concentrations of radiocesium were all located in the basin of the tributaries. Actually, rice with a radiocesium concentration of $>50 \mathrm{~Bq} / \mathrm{kg}$ was not produced from paddy fields on the bank of the mainstream, even though potassium concentrations in the soil were low. These paddy fields were located only a few hundred meters from fields in the basin that produced rice with high concentrations of radiocesium. Hence, there is a possibility that some geographical factors increase radiocesium uptake.

\subsection{No Decrease of Radiocesium in Rice}

After 2012, we continued to cultivate rice continuously in the paddy fields in Oguni with high radiocesium concentrations, in collaboration with the local community, the City, and other Universities (Nemoto 2014). We originally estimated that the uptake of radiocesium in rice would decrease year by year. However, to our surprise, there has been almost no change since 2013. This fact suggests that the amount of radiocesium which is responsible for producing rice with a high radiocesium concentration still exists in the paddy fields without being fixed by the soil. Certainly, there is a possibility that the irrigation water acted as a source of radiocesium 
because the reservoirs contained $3-4 \mathrm{~Bq} / \mathrm{L}$ of radiocesium one year after the accident. However, radiocesium in the reservoirs decreased sharply after 2013, and at present, radiocesium $>1 \mathrm{~Bq} / \mathrm{L}$ has not been detected in the irrigation water from Oguni. The inflow of radiocesium via the irrigation water to all paddy fields has been about $100 \mathrm{~Bq} / \mathrm{m}^{2}$ since 2013, and this is much lower than the amount absorbed by the rice. It seems that irrigation water will not become a source of radiocesium for rice at present unless mud at the bottom of reservoirs mobilizes.

Because we believe water is not the source of radiocesium, the next possibility is the soil. Radiocesium deposited on soil after the nuclear accident is usually fixed by clay mineral over time, and thus the amount of exchangeable radiocesium, i.e. radiocesium absorbed by roots decreases with time. To verify this phenomenon, we investigated the fixation of deposited radiocesium on soil in paddy fields in Oguni. One year after the accident (i.e., 2012), about $80 \%$ of the deposited radiocesium was fixed by the soil, and the other $20 \%$ was exchangeable radiocesium. Surprisingly, the fixation of cesium to soil has not progressed much in 5 years (2012-2016), and about 15\% of the radiocesium is still in an exchangeable form which can be absorbed by plants.

Of course, not all paddy fields in Fukushima Prefecture are in the same situation. As stated above, the radiocesium uptake dropped below $100 \mathrm{~Bq} / \mathrm{kg}$ in three-quarters of the 60 experimental fields in Oguni without any measures to control radiocesium uptake in 2012. Exchangeable radiocesium in some paddy fields has decreased to 5\%.

\subsection{Summary of the Experiments Performed in Oguni, Date City}

These results outlined above raises two questions. First, as mentioned previously, it is necessary to continue applying potassium fertilizer. Indeed, thanks to the municipalities' exhaustive instructions to farmers about applying additional potassium fertilizer, no rice in Fukushima Prefecture with radiocesium over the standard value (100 Bq/kg) has been detected since 2015 (Fukushima Association for Securing Safety of Agricultural Products). However, judging from the result of the experimental cultivation in Oguni, the concentration of radiocesium in rice might increase over the standard value again if we moderate applications of potassium in the paddy fields where cesium does not easily fix to soil, or where radiocesium is mobile in the soil. It is necessary for the Government to take responsibility not only for providing farmers with potassium fertilizer as grant aid but also for its application, in order to complete the control measure of radiocesium.

Secondly, we need to apply our research findings to continually investigate regions where cultivation will be resumed in the future. For example, some farmers returning to regions where the evacuation order has just been lifted will want to cultivate rice again. When considering risks of uptake of radiocesium by rice cultivated in these regions, the data obtained in Oguni will be very important and applicable. 
Acknowledgment The authors would like to thank Riona Kobayashi (The University of Tokyo) for her technical assistance.

\section{References}

Fukushima Association for Securing Safety of Agricultural Products. https://fukumegu.org/ok/ kome/

Ministry of Agriculture, Forestry and Fisheries, and Fukushima Prefecture (2014) Factors causing rice with high radioactive cesium concentration and its countermeasures. http://www.maff. go.jp/j/kanbo/joho/saigai/pdf/kome.pdf

Nemoto K (2014) Transfer of radioactive cesium to rice (Fourth report). http://www.a.u-tokyo. ac.jp/rpjt/event/20141109slide5.pdf

Nihei N, Tanoi K, Nakanishi TM (2015) Inspections of radiocesium concentration levels in rice from Fukushima Prefecture after the Fukushima Dai-ichi Nuclear Power Plant accident. Scientific Reports 5, Article number: 8653-8658 2015/3

Open Access This chapter is licensed under the terms of the Creative Commons Attribution 4.0 International License (http://creativecommons.org/licenses/by/4.0/), which permits use, sharing, adaptation, distribution and reproduction in any medium or format, as long as you give appropriate credit to the original author(s) and the source, provide a link to the Creative Commons license and indicate if changes were made.

The images or other third party material in this chapter are included in the chapter's Creative Commons license, unless indicated otherwise in a credit line to the material. If material is not included in the chapter's Creative Commons license and your intended use is not permitted by statutory regulation or exceeds the permitted use, you will need to obtain permission directly from the copyright holder. 